\title{
ALPINE VEGETATION ECOTONE DYNAMICS IN GANGOTRI CATCHMENT USING REMOTE SENSING TECHNIQUES
}

\author{
C. P. Singh ${ }^{1}$, S. Panigrahy and J. S. Parihar ${ }^{\mathrm{c}}$ \\ EPSA, Space Applications Centre (ISRO), Ahmedabad, 380015, India \\ ${ }^{1}$ Email: cpsingh@sac.isro.gov.in
}

KEY WORDS: Alpine vegetation ecotone; treeline, remote sensing, normalized difference vegetation index (NDVI), Gangotri.

\begin{abstract}
:
Analysis of the satellite imagery reveals two different perspectives of the vegetation ecotone dynamics in Gangotri catchment. On one hand, there is evidence of upward shift in the alpine tree and vegetation ecotone over three decades. On the other hand, there has been densification happening at the past treeline. The time series fAPAR data of two decades from NOAA-AVHRR confirms the greening trend in the area. The density of trees in Chirbasa has gone up whereas in Bhojbasa there is no significant change in NDVI but the number of groves has increased. Near Gaumukh the vegetal activity has not shown any significant change. We found that the treeline extracted from satellite imagery has moved up about $327 \pm 80 \mathrm{~m}$ and other vegetation line has moved up about $401 \pm 77 \mathrm{~m}$ in three decades. The vertical rate of treeline shift is found to be $11 \mathrm{~m} / \mathrm{yr}$ with reference to 1976 treeline; however, this can be $5 \mathrm{~m} / \mathrm{yr}$ if past toposheet records $(1924-45)$ are considered as reliable reference. However, the future IPCC scenario based bioclimatic fundamental niche modelling of the Betula utilis (a surrogate to alpine treeline) suggests that treeline could be moving upward with an average rate of $3 \mathrm{~m} / \mathrm{yr}$. This study not only confirms that there is an upward shift of vegetation in the alpine zone of Himalayas, but also indicate that old vegetation ecotones have grown denser
\end{abstract}

\section{INTRODUCTION}

The alpine life zone is globally distributed, from polar to tropical latitudes and occurs across oceanic and continental climates. Owing to the compression of thermal zones and to isolation caused by low-temperature, the alpine ecosystem usually having distinct biological communities and high level of endemism, respond very sensitively to temperature change. Also, this area being among the remaining most pristine environments on earth, least influenced by anthropogenic activities provides an ideal 'natural laboratory' for climate impact research studies.

Across the altitudinal alpine ecosystem, the number of trees per unit area often decreases from the lower to upper altitude owing to the harsher environment at higher altitudes, followed by other vegetations or grasslands. As for as defining the boundary as "treeline" or "vegetation line" is concerned, it is groups of trees, i.e. patches of uppermost undisturbed forest, connected with a line or shrubs/grassland patches connected with a line, respectively. Usually a treeline is not a clear-cut line between forest and nonforest vegetation, but a transition zone (ecotone) from dominant trees to shrubs or grassland.

\subsection{Remote sensing of alpine ecotone dynamics}

Remote sensing due to its synoptic view and historical records for a wide area is important tool to study alpine ecotone dynamics. In remote sensing studies of vegetation, spectral vegetation indices are normally used in monitoring vegetation density. Among all vegetation indices, normalised difference vegetation index (NDVI) is the most popular. It has been broadly used in detecting vegetation change, vegetation greenness, and vegetation activity at both landscape and global scales (Myneni et al., 1997a; Kawabata et al.; 2001, Steven et al., 2003). NDVI had good correlation with canopy cover and leaf area index and it had better performance than single band or combined use of other bands in estimating crown closure (Xu et al., 2003). Unlike the nominal land use type in classified images, NDVI has the advantage of quantifying continuous changes to vegetation within each pixel and it can distinguish between bare ground areas and partially forested areas, or densely forested areas. Density of forest can also be an indicator of changes in the ecology of treelines, which may precede any detectable movement of boundaries in remotely sensed images. Most forests in treeline areas are sparse, with low canopy coverage. A greater growth response (i.e. grew denser) in treeline forests compared to reference treeline forests makes it possible to get detected using remote sensing techniques.

Another most obvious indicators of ecological impacts of climate change are phenological changes. Phenological events like leaf initiation, leaf colouring, and leaf fall can be observed by satellites. The timing of these events is often closely related to temperature and the amount and timing of precipitation. In temperate zones an increase in temperature leads to an earlier start of the growing season and a may be a later end. The length of the growing season is expected to increase with warming (Myneni et al., 1997a). Only in those places where environmental conditions like drought, flooding or large amounts of snowfall limit plant growth will an increase in temperature not immediately result in a lengthening of the growing season. Plants are flexible in adjusting the timing of their phenological events to changes in climate conditions.

The treeline is a space and time related phenomenon. When assessing treeline sensitivity and its potential response to changing environmental conditions, spatial scale plays an important role (Holtmeier \& Broll, 2005). The 'treeline', defined by a certain coverage (e.g. $30 \%$ or $40 \%$ ), can be mapped from satellite images or other remote sensing techniques (Rees et al., 2002). The term "line" is used as a convention, because, in reality, 
ISPRS Archives XXXVIII- 8/W20; Workshop Proceedings: Earth Observation for Terrestrial Ecosystems

these occur in patches and never manifest as a continuous "line". What might be an obvious line from great distance offers a rather gradual, fragmented picture in situ. So the term "line" does not imply a physical line, but rather refers to a boundary or obvious transition zone at the above level of precision. The minimum height for a tree should be $2-3 \mathrm{~m}$ at treeline (Kullman, 1979). However, in the context of remote sensing, this definition is subjective and refers to the transition of clear-cut tree zone to alpine vegetation zone. The alpine other vegetation line is the transition from any form of vegetation including mosses, lichen to permanent snow line. However, from remote sensing perspective, since, many form of low stature vegetation/scattered forms and moss/lichens may not be amenable with high accuracy, the line refers to the upper limit of discernable vegetation before the snow line.

\subsection{Alpine treeline and climate change}

Temperature-limited environments, such as boreal and arctic regions, are thought to be very sensitive to global warming. Under projected global warming scenarios, alpine vegetation dynamics, as a core aspect of mountain landscape transformation, is a key subject in detecting climate-dependent ecological processes (Kullman, 2004). Factors related to tree growth or seed production and germination such as temperature, precipitation, solar radiation, and wind or soil nutrient can all inhibit the treeline from moving further towards higher latitudes or altitudes (Grace et al., 2002). Any change in the climate, which perturbs the vegetation-climate equilibrium, will lead to significant changes in the demographic patterns of these species. Amongst these, temperature is the most common limiting factor and affecting various aspects of vegetation dynamics, such as photosynthesis, respiration, seed germination and nutrient cycling, especially in these areas where temperature is not favourable to vegetation growth (Körner \& Paulsen, 2004). Global warming can be expected to alleviate these constraints, provide chances for plants to invade bare areas, and improve growth (enhanced productivity, stem density and canopy coverage) of already established plants in severe environments (Kullman, 1990). For example, in an area where the presence of vegetation is limited by a short growing season caused by failure to reach a minimum threshold temperature, global warming can prolong the growing season (Grace et al., 2002). Increasing forest areas combined with increased productivity will promote carbon sequestration in high latitude/altitude regions and may act as negative feedback on climatic warming (Dixon et al., 1994). Dynamics of treeline ecotone can therefore be utilised as an indicator of climate change, especially temperature change.

Previous studies whether field or remote sensing based have indicated treeline shift and attributed it to climate change but the rate of shift varies from place to place with species and largely depends on species sensitivity to climate (Grabherr et al., 1994; Holtmeier \& Broll, 2005; Dubey et al., 2003; Adhikari, 2003; Panigrahy et al., 2010; Kullman, 1990; Grace et al., 2002; Danby and Hik, 2007).

Response of vegetation to global warming around the treeline ecotone has been reported as increased forest density and increased radial and vertical growth rather than just advancing of treeline forests (Kullman, 2007). Response to global change may be easier to detect inside treeline forests as a changed density, because an environment favourable to tree presence has already formed within treeline forests. Myneni et al 1997a reported increased plant growth from 1981 to 1991 in the northern arctic latitudes and related it to increased $\mathrm{CO}_{2}$ levels and warmer temperatures. Similarly, Gottfried et al., 1998 hypothesized that the alpine-nival ecotone boundary in the European Alps will probably be affected by climatic change, but that the vegetation patterns at this interface zone will also be related to topographic relief. A tree-ring counting study (Kar et al., 2002), demonstrated that Betula utilis growing on terminal moraines of Gangotri are 125-200 years in age with abrupt growth surge found during the late $20^{\text {th }}$ century. Strong correlation between tree growth and winter temperature showed that the winter warmth is one of the main factors responsible for it. This growth surge is closely associated with the area vacated by the Gangotri glacier.

\section{MATERIAL AND METHODS}

\subsection{Study Area}

The Gangotri glacier area, situated in Uttarkashi district of Uttarakhand state in Western Himalaya, India (figure 1) is one of the largest Himalayan glaciers, which is about $30.20 \mathrm{~km}$ long (GSI, 1999) with its width varying from 0.5 to $2.5 \mathrm{~km}$. It is a valley-type glacier and it flows to NW direction. This is bounded between $30^{\circ} 43^{\prime} 17^{\prime \prime} \mathrm{N}-31^{\circ} 03^{\prime} 02^{\prime \prime} \mathrm{N}$ (lat.) and $78^{\circ} 56^{\prime} 06^{\prime \prime} \mathrm{E}-$ $79^{\circ} 17^{\prime} 23^{\prime \prime} \mathrm{E}$ (long.), extending in height from $3030 \mathrm{~m}$ to $7076 \mathrm{~m}$. a.m.s.l, with slope angle varying between zero and 82 degrees (values from ASTER GDEM).

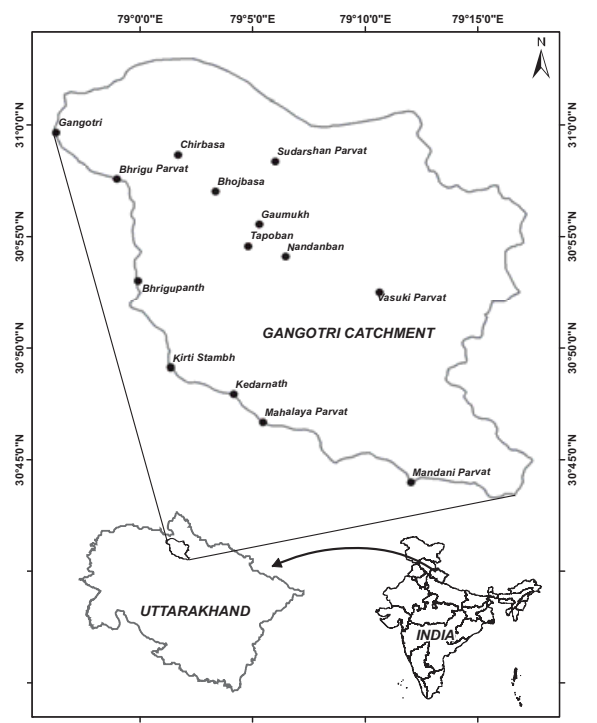

Figure 1. Location map of the study area

The southwest Indian monsoon with an average annual precipitation of $1550 \mathrm{~mm}$ (IMD, 1989) influences the climate of the area. The annual mean temperature ranges from $-7^{\circ} \mathrm{C}$ to $+3^{\circ} \mathrm{C}$. The microclimate of this region may be affected by both the valley aspect and altitude. The total study area as marked in figure 1 is $706.6 \mathrm{~km}^{2}$. The Gangotri glacier catchment has total $258.56 \mathrm{~km}^{2}$ of glacierized area, out of which the Gangotri system comprises $109.03 \mathrm{~km}^{2}$ (Naithani et al., 2001). This glaciated catchment is receding with the average rate of $19 \mathrm{~m} / \mathrm{yr}$ (Shankar \& Srivastava, 1999). Remote sensing based study by Bahuguna et 
al, 2007 also stated that, the annual rate of retreat could be $18 \mathrm{~m}$ (during year $2000-2001$ ), however, the long term analysis by them $(1962-2000)$ indicated receding rate of $40 \mathrm{~m} / \mathrm{yr}$, which is also in accordance with the Mukherjee \& Sangewar, 2001.

The broadleaved thick forests are rare in this valley, but the arid element Himalayan cedar (Cedrus deodara) dominates the vegetated slopes up to treeline (Naithani et al., 2001). The tree which reaches to the highest elevation $(\approx 4100 \mathrm{~m}$. a.m.s.l.) near Bhojbasa is Indian birch (Betula utilis), locally known as Bhojpatra and forms the part of present-day treeline. Beginning from Gaumukh, the valley ends at Gangotri $(32,00 \mathrm{~m}$ a.m.s.l.) after $18 \mathrm{~km}$. The Bhagirathi passes through the heart of the valley. Chirbasa at the distance of $9 \mathrm{~km}$ from Gangotri is the forest of stately pines at the height of $3,400 \mathrm{~m}$ across the Chirbas Nala (stream). At Tapoban and Nandanvan the alpine meadows are found during late summer and monsoon. These alpine meadows are dominated by grass, Artemisia, Juniperus, Ephedra and Salix along with other taxa (Kar et al., 2002).

\subsection{Data Used}

The satellite data (table 1), meteorological data from IMD (Srivastava et al., 2008) and digital elevation model (DEM) data from The Advanced Spaceborne Thermal Emission and Reflection Radiometer (ASTER) were used to delineate and characterise the tree and vegetation ecotones (table 2). Ground truth information collected through collaborative agencies and other ancillary datasets (table 3 ) were also used.

\begin{tabular}{|l|l|l|l|}
\hline Acquisition & Platform & Sensor & $\begin{array}{l}\text { Spatial } \\
\text { Resolution }\end{array}$ \\
\hline $\begin{array}{l}\text { Nov.19, 1976 } \\
\text { Oct.15, 2006 }\end{array}$ & $\begin{array}{l}\text { Landsat 2 } \\
\text { IRS-P6 }\end{array}$ & $\begin{array}{l}\text { MSS } \\
\text { LISS-III }\end{array}$ & $\begin{array}{l}57 \mathrm{mtr} \\
23.5 \mathrm{mtr}\end{array}$ \\
\hline
\end{tabular}

Table 1. List of data used

\begin{tabular}{|c|c|c|c|}
\hline Period & Product & $\begin{array}{l}\text { Platform/ } \\
\text { Sensor }\end{array}$ & $\begin{array}{ll}\text { Spatial } \\
\text { temporal } \\
\text { Resolution }\end{array}$ \\
\hline Jan.1999-Dec.2008 & NDVI* & $\begin{array}{l}\text { SPOT- } \\
\text { VGT }\end{array}$ & $1 \mathrm{~km} / 10$ Days \\
\hline Jul.1981-May.2001 & fAPAR & $\begin{array}{l}\text { NOAA- } \\
\text { AVHRR }\end{array}$ & $16 \mathrm{~km} /$ Monthly \\
\hline Dec.1999-Jun.2008 & DEM V1.0 & $\begin{array}{l}\text { Terra- } \\
\text { ASTER }\end{array}$ & $30 \mathrm{~m} /$ Once \\
\hline
\end{tabular}

Table 2. Satellite data Products used

\subsection{Methodology}

2.3.1 Alpine tree and vegetation ecotone: The study involves data selection, pre-processing, vegetation index calculation; thresholding based treeline and other vegetation line delineation and change analysis. Orthorectified and cloud free $(<10 \%)$ IRSP6 LISS-III imagery of 2006 (UTM/WSG84 projection) was used to delineate the current status of treeline and vegetation line. Orthorectified and cloud free $(<10 \%)$ Landsat-2 MSS imagery of 1976 was used as reference data for change analysis. Digital numbers were converted to reflectance and an image based atmospheric correction was used for data normalization (Chavez, 1996). NDVI images were generated using these set of corrected and normalized data sets (table.1). Although the differences are relatively small, the sensors on different satellite instruments measure somewhat different wavebands, and systematic differences may occur. Therefore, based on simulation and ground experiments conducted by Steven et al 2003, we used following coefficients to normalize the LISS-III data w.r.t. MSS:

\begin{tabular}{|c|c|c|c|}
\hline Period & Parameter & Source & Resolution \\
\hline $1969-2005$ & $\begin{array}{l}\text { MaxT, MinT } \\
\text { and MeanT }\end{array}$ & $\begin{array}{l}\text { NCC, IMD, } \\
\text { Pune, India }\end{array}$ & 1deg / Daily \\
\hline $\begin{array}{l}30 \quad \text { years } \\
\text { normal } \\
(1971- \\
2000)\end{array}$ & $\begin{array}{l}\text { District } \\
\text { Climate } \\
\text { Normal }\end{array}$ & $\begin{array}{l}\text { NCC, IMD, } \\
\text { Pune, India }\end{array}$ & $\begin{array}{l}\text { District } \\
\text { level / One }\end{array}$ \\
\hline $2010-2080$ & $\begin{array}{l}\text { A1B Scenario : } \\
\text { Bioclimatic } \\
\text { Indices }\end{array}$ & $\begin{array}{l}\text { Ramirez and } \\
\text { Jarvis, } 2008\end{array}$ & $\begin{array}{l}1 \mathrm{~km} \\
\text { Decadal }\end{array}$ \\
\hline $1924-45$ & $\begin{array}{l}\text { Topographic } \\
\text { information }\end{array}$ & $\begin{array}{l}\text { Survey of } \\
\text { India } \\
\text { Toposheet }\end{array}$ & $\begin{array}{l}\text { linch } \\
\text { series }(1: 63 \text {, } \\
360)\end{array}$ \\
\hline
\end{tabular}

Table 3. Ancillary data used

$\mathrm{NDVI}_{\text {Landsat MSS }}=-0.020+1.065 * \mathrm{NDVI}_{\mathrm{IRS}}$

NDVI used as surrogate to define the treeline and vegetation line ecotones tend to have more NDVI at treeline ecotones compared to other vegetation ecotones. The threshold NDVI values were arrived taking signatures from the known dense forest patches of Sub Alpine Forests (SAFs), and that of alpine meadows (locally known as "buggyals"). Connecting with iso-NDVI-line based on bi-cubic spline interpolation technique and filtering small spurious contours on the defined threshold gave us the treeline and other vegetation line. Corrections for hill shadow areas were carried out using visual editing

The care was taken to select the same time frame imageries; however, the NDVI can be biased by plant phenology. Therefore, phenologically normalised coarse treeline and vegetation line was generated using hyper-temporal SPOT-VGT data and correctness of the current ecotones was ascertained. This was achieved by extracting the time temporal normalised ecotones with standardised principal components analysis (PCA) on 108 stacked SPOT-VGT images for 3 years $(2005-2007)$. Standardised PCA (Leica, 2005) essentially compressed bulk of the variability into 4 images. The uncorrelated components were ordered in the amount of variance explained in the data. The first PCA was subjected to "treeline" and "other vegetation line" extraction with similar approach described above and all current were found comparable, however, the ecotonal details were less pronounced due to coarser resolution of SPOT-VGT NDVI. Phenological correctness for past ecotones could not be ascertained due to non-availability of hyper temporal data for that time frame.

2.3.2 Change analysis: Station points at every $30 \mathrm{~m}$ were generated on the treeline and other vegetation line ecotones. The DEM values were extracted for each station point locations. The change in ecotones were studied as a function of shift in altitude from past (1976) to current (2006) position. Equal numbers of station points generated over past and current ecotones were joined to form shift lines. The 'from' and 'to' nodes having elevational information extracted from DEM were subtracted to populate the shift values in the vector table. Surface length was also computed using DEM as a surface layer. GIS queries were 
made to locate the maximum shift zones to spot the direction and magnitude of the change.

2.3.3 Uncertainty analysis: Since different sets of satellite data and products were used to extract the treeline, vegetation line and its altitude determination, the estimates are subject to inherent errors associated at each step. The vegetation index interconversion precision is $1-2 \%$ (Steven et al., 2003). Preproduction estimated accuracies for the ASTER global DEM product were $20 \mathrm{~m}$ for vertical data and $30 \mathrm{~m}$ for horizontal data at 95\% confidence level (web1). Here, both horizontal and vertical errors in the DEM can contribute to vertical errors in the position of the treeline, therefore mapping accuracy (RMS error) of the treeline were used to find out the effect on vertical errors. Vertical errors due to horizontal treeline mapping errors were taken into account in relation to each pixel slope (in degrees) on the treeline. The vertical error of DEM was combined with the vertical errors due to horizontal misalignment in both past and current treeline separately. This was achieved by calculating the quadratic sum of the errors. These errors were then used to calculate the overall uncertainty in alpine treeline shift.

2.3.4 Greening trend and phenological dynamics: The overall greening trend was studied for 2 decades using monthly fAPAR product (Myneni et al 1997b). The specific greening trend was also studied using 10 days composite data of SPOT-VGT NDVI for 1 decade (http://free.vgt.vito.be). Stratified samples were taken along each category (past and current treeline, past and current vegetation line) with elevation, aspect and slope criterions with AOI of $\approx 1 \mathrm{~km}^{2}$. The SPOT-VGT NDVI was also used for studying the phenological dynamics. For smoothing of time-series and to get a good estimate of the phenological parameters, TIMESAT (Jönsson \& Eklund, 2004) was used. The SavitzkyGolay curve follows the NDVI data better, than the asymmetric Gaussian curve therefore hereby preferred. Starting from the left base level or minimum, the beginning of a season were defined from the filtered or fitted functions as the point in time for which the value has risen by a certain amount; here it was set to inflection point of the distance between the left base level and the maximum. The end of the season was defined in a similar way.

2.3.5 Fundamental niche modelling: The studies so far conducted strongly indicate that the alpine world is facing major changes despite the modest increase in temperature. The knowledge generated by the current monitoring system is a precondition for models that predict the impact of a possibly warmer future. To ascertain the future rate of change in treeline we used known Betula utilis locations and trained the Genetic Algorithm for Rule-set Production: GARP, an environmental niche model (Stockwell \& Peters, 1999) on the bioclimatic indices (Hijmans et al., 2005) for future projections based on IPCC scenarios (Ramirez \& Jarvis, 2008).

\section{RESULTS AND DISCUSSION}

\subsection{Change in treeline and vegetation line}

The treeline in study zone is confined between $30^{\circ} 55^{\prime} 32.3^{\prime \prime} \mathrm{N}-$ $31^{\circ} 01^{\prime} 36^{\prime \prime} \mathrm{N}$ (lat.) and $78^{\circ} 56^{\prime} 6.5^{\prime \prime} \mathrm{E}-79^{\circ} 06^{\prime} 24.5^{\prime \prime} \mathrm{E}$ (long.). The digital comparison of the treeline between year 1976 and 2006 found that it has changed in the past 3 decades (figure 2). All forested cells along the past treeline ecotone were still forested in
2006 with same or increased NDVI while certain non forested pixels in 1976 are converted to forest in 2006. The treeline had shown about $327 \pm 80 \mathrm{~m}$ and other vegetation line had shown about $401 \pm 77 \mathrm{~m}$ of upward shift in the past 3 decades (table 4 ). The changes in geographical area under the different ecotones are also significant (table 5).

\begin{tabular}{|l|l|l|l|l|}
\hline S.N. & Ecotone & $\begin{array}{l}\text { Mean Alt. } \\
(1976)\end{array}$ & $\begin{array}{l}\text { Mean Alt. } \\
(2006)\end{array}$ & Change \\
\hline 1. & Treeline & 4120 & 4447 & 327 \\
2. & Vegetation line & 4933 & 5334 & 401 \\
\hline
\end{tabular}

Table 4. Altitudinal position of ecotones (in metres)

\begin{tabular}{|l|l|l|l|l|}
\hline S.N. & Ecotone & $\begin{array}{l}\text { Area } \\
(1976)\end{array}$ & $\begin{array}{l}\text { Area } \\
(2006)\end{array}$ & Change \\
\hline 1. & Treeline & 20.41 & 26.74 & 6.33 \\
2. & Vegetation line & 46.29 & 55.35 & 9.06 \\
\hline
\end{tabular}

Table 5. Treeline and vegetation line area (in $\left.\mathrm{km}^{2}\right)$

\subsection{Greening trend}

The mean fAPAR data showed the greening trend (figure 3) at the treeline transition zone. A significant positive trend in mean fAPAR in 20 years has been observed. The slope was 0.004 per year. Ring-width chronology of Pinus wallichiana (AD 16501999) in Gangotri (Singh \& Yadav, 2000) also confirms that there has been rapid greening especially in past three to four decades. SPOT-VGT based results indicated that during growing season (May-Nov) along rising elevation the greening trend is slowly diminishing. It was also found that near past and current treeline as well as near past vegetation line there is greening trend. The points studied near current vegetation line do not show significant greening trend. Each sample point gained an average of 0.10 (standard deviation, $\sigma 0.03$ ) of NDVI in 10 years (figure 4). However, Landsat-MSS and IRS-LISS-III NDVI change in 30 years has been 0.10 to $0.20(\sigma 0.06)$.

Relative to NDVI in each point, the $\sigma$ was smaller in higher altitudes, suggesting that vegetations (meadows) are evenlydistributed and major disturbances have been absent during this period. During 3 decades, the sparse stands at past treeline transformed into closed stands (NDVI increasing from 0.20 to $\geq$ 0.50 ), with existing closed stands increasing in area and advancing their upper border. The density of trees in Chirbasa (NDVI 0.1 to 0.3 ) has gone up whereas in Bhojbasa there is no significant change but the number of groves has increased. The 10 years NDVI data of SPOT-VGT also confirms the same. Near Gaumukh the vegetal activity has not shown any significant change and the same has been confirmed from the NDVI time series data of 10 years. Moreover, the NDVI over the past treeline and past vegetation line are showing greening trend as compared to the reference NDVI, indicating that growth of the treeline apparently exceeded that of the reference treeline and had grown denser. The result shows that the treeline is advancing to somewhat higher elevations in response to the climatic amelioration. It was also found that these changes correlated positively with temperature trends (figure 5). 


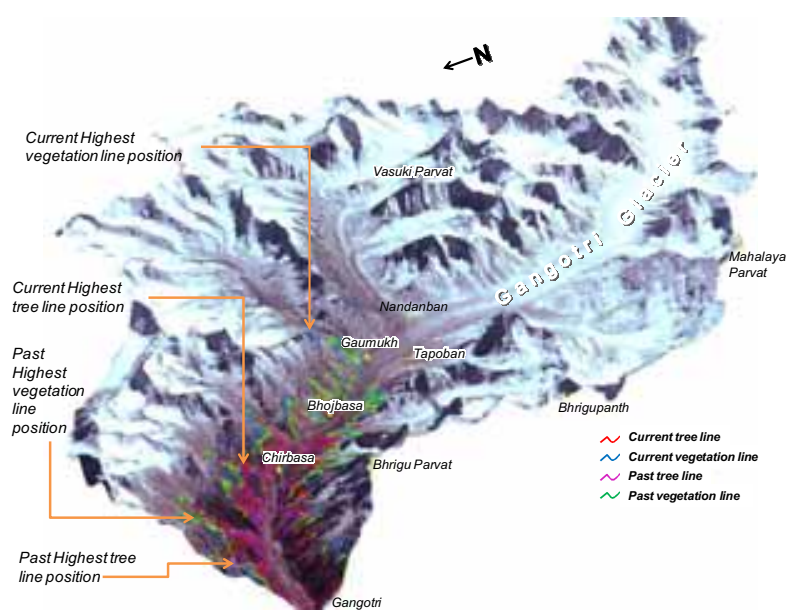

Figure 2. Perspective view showing the position of treeline and vegetation line (current/past) over IRS-P6-LISS-III FCC.

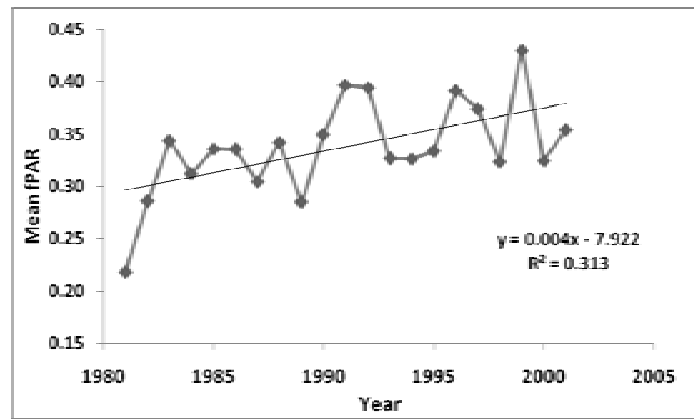

Figure 3. Mean fAPAR in the past decades (1981 to 2001) in Gangotri region.

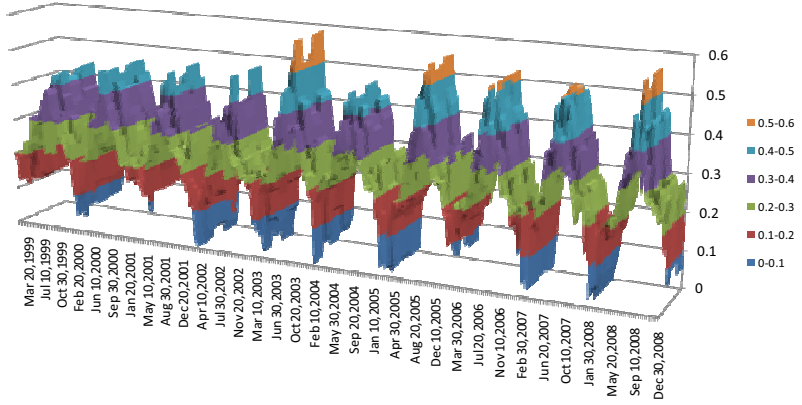

Figure 4. Treeline NDVI time series of 10 years.

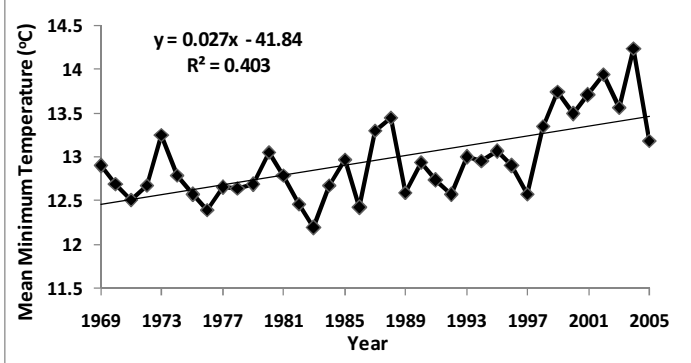

Figure 5. Mean Minimum temperature $\left({ }^{\circ} \mathrm{C}\right)$ trend in the past decades in Gangotri region. (data Source: National Climate Centre, India Meteorological Dept., Pune, Srivastava et al 2008)

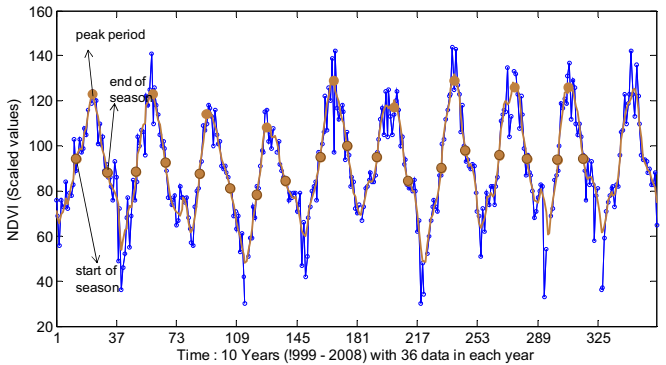

Figure 6. Scaled NDVI values for 10 years $(1999-2008)$ from SPOT-VGT over treeline (Mean Altitude $3282 \mathrm{~m}$ ) in Gangotri.

Time is in 10 day steps. [NDVI $=$ scaled value $* 0.004)-0.1$ ]
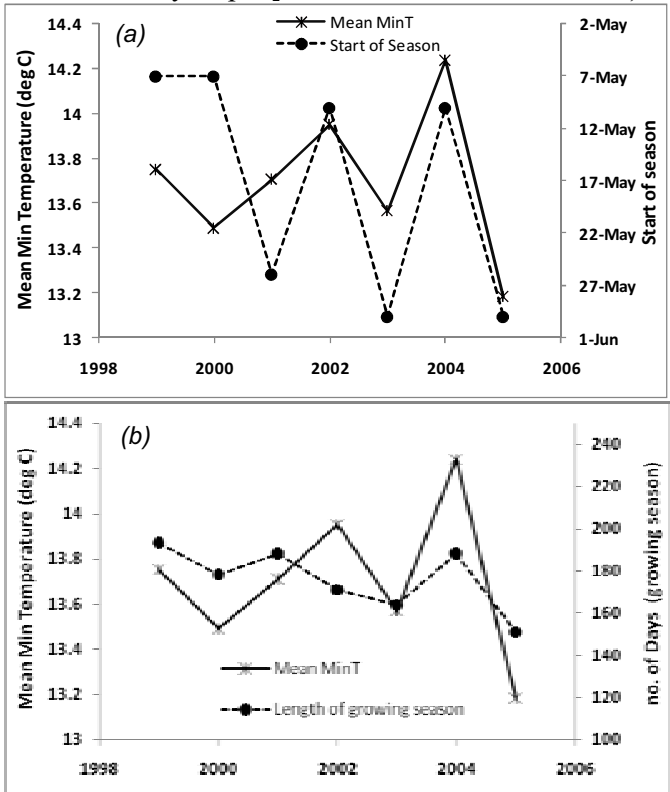

Figure 7. (a): Start of the season (from NDVI time series) Vs the Mean Min annual temp. $\left[r^{2}=-0.60\right]$. (b): Growing season Vs

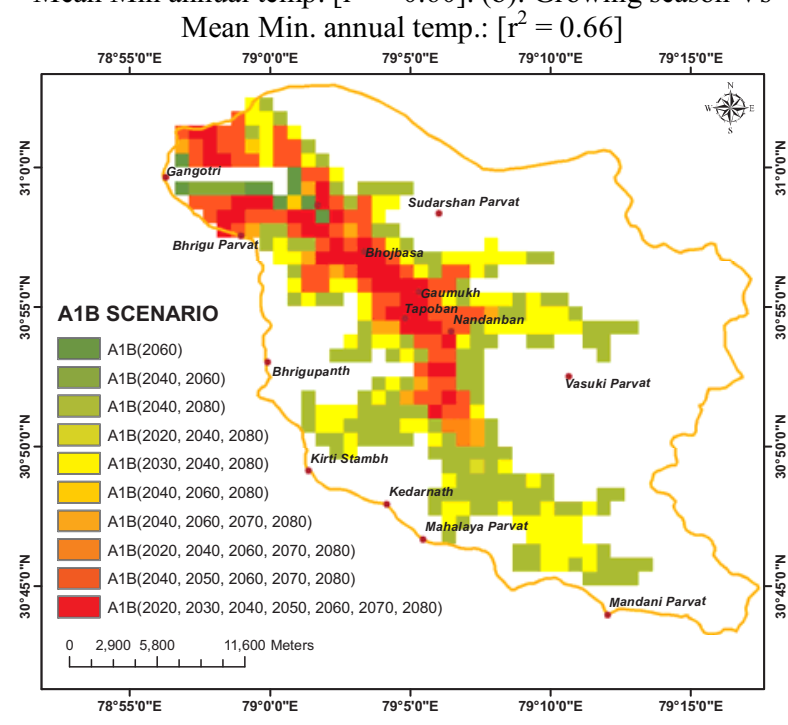

Figure 8. IPCC scenario (A1B) based projected future fundamental environmental niche of Betula utilis. 


\subsection{Phenological dynamics}

Figure 6 shows scaled Savitzky-Golay filtered NDVI data over a past treeline to current treeline transition zone in Gangotri area. This clearly indicates that, the area is dominated by a one seasonal (uni-modal) cycle. The beginnings and ends of seasons were located fairly close to each other in all the years. Near the treeline the season starts in May and ends in November with peak period in August (NDVI: $0.33-0.43$ ). The variability in the seasonality parameters can be explained by meteorological data. Moisture availability is unlikely to be much significant constraint on plant growth as the district normal precipitation ranges from $10.7 \mathrm{~mm}$ in October to $455.4 \mathrm{~mm}$ in August with rainy days varying from 1 to 19 in October and August, respectively. It was found that, the starting date of the season fluctuates with the changing temperature in the treeline area. The increase in mean minimum temperature starts the greening season early and has bearing on the length of growing season with correlation coefficient of 0.66 (figure 7(b)). Initially, the start of the season is not in accordance with the general trend (figure 7(a)), may be due to increasing winter precipitation on the starting date of the growing season. The seasonality of the vegetation in this area, however, is well developed and can be explained with meteorological variables.

\subsection{Future scenario of alpine ecotone and change dynamics}

Betula utilis being the treeline species in this region was selected for GARP based fundamental environmental niche modelling using 19 bioclimatic indices generated for A1B scenarios for 2020 to 2080 at every decade. The analysis of the output (figure 8 ) shows that the treeline is expected to go further up to $5914 \mathrm{~m}$ in 2080 as compared to 5347 in year 2010. The average shift from reference year 2010 shows that the fundamental niche of Betula utilis can move upward by $184 \mathrm{~m}$ in 7 decades. This shows that the treeline could be moving upward with a modest average rate of $3 \mathrm{~m} / \mathrm{yr}$, if all other conditions of germination and survival are found favourable.

The treeline found in year 1976 at $4120 \mathrm{~m}$ height is also confirmed by the toposheet, which was compiled using the one inch series toposheets surveyed during $1924-45$. Looking at this, the conservative estimate of the vertical rate of treeline shift could be $5 \mathrm{~m} / \mathrm{yr}$. However, keeping the reference as year 1976 from this remote sensing based study the rate of change is found to be $11 \mathrm{~m} / \mathrm{yr}$. The observed rate of upward shift of pine in this region is higher in comparison to other species recorded in Alps and elsewhere. This fact is also supported earlier by Dubey et al., 2003. This is presumably a phenomenon noted in most of the alpine treeline zones in the world, but we cannot neglect the interference of human activities particularly to this glacier. The rate of change is higher than other alpine areas may be due to the increased anthropogenic activities (high influx of tourists, pilgrims, mountaineers and trekkers) in this area. Enhanced treeline growth results concluded in this study is in agreement with previous research carried out in Russia (Gorchakovsky \& Shiyatov, 1978), Sweden (Kullman, 1990), Canada (Danby \& Hik, 2007), China (Zhang, 2008), Norway (Aas, 1969) and Indian Himalaya (Chauhan et al., 2000, Panigrahy et al., 2010).

\section{CONCLUSION}

Analysis of the satellite imagery reveals two different perspectives of the vegetation ecotone dynamics in Gangotri catchment. On one hand, there is evidence of a shift in the treeline in 3 decades. On the other hand, the absolute NDVI value of the past treeline has also increased. The leaf phenology of the area is found controlled with the known drivers of climatic parameters and forms the basis for future investigations on these aspects.

The treeline extracted from satellite imagery has shown about $327 \pm 80 \mathrm{~m}$ and other vegetation line has shown about $401 \pm 77 \mathrm{~m}$ of upward altitudinal mean shift in three decades. The vertical rate of treeline shift is found to be $11 \mathrm{~m} / \mathrm{yr}$ with reference to 1976 treeline; however, this can be $5 \mathrm{~m} / \mathrm{yr}$ if past toposheet records $(1924$ - 45) are considered as reliable reference. However, the future bioclimatic fundamental niche modelling of the Betula utilis species (as a surrogate to treeline) shows that treeline could be moving upward with a rate of $3 \mathrm{~m} / \mathrm{yr}$.

Climatic warming is likely to lead to different impacts on these various vegetation types along the elevation gradient. The scope of expansion of canopies in past treeline is going to be limited, and increment of NDVI resulting from canopy growth is also expected to be minor. However, the sparse birch forest can rapidly expand its canopy coverage through invading open areas or expanding the canopy within existing stands given a favourable climate change. In fact, the treeline forest may benefit more from global warming than the mature forests in the lower altitudes because the treeline forest is more limited by temperature.

\section{REFERENCES}

Adhikari, B.S., 2003. Ecological attributes of vegetation in and around Nandadevi National Park. In: UAF, Biodiversity Monitoring Expedition Nandadevi, 2003. A report to the MoEF, GoI, Uttaranchal Forest Dept, Dehradun, pp.15-38.

Aas, B., 1969. Climatically raised birch lines in southern Norway 1918-1968, Norsk Geografisk Tidsskrift, 23, pp. 119-130.

Bahuguna, I. M., Kulkarni A.V., Nayak, S., Rathore, B.P., Negi, H.S. and Mathur, P., 2007, Himalayan glacier retreat using IRS 1C PAN stereo data, International Journal of Remote Sensing, 28(2), pp. 437-442.

Chauhan, M.S., Mazari, R.K. and Rajagopalan, G., 2000. Vegetation and climate in upper Spiti region, Himachal Pradesh during late Holocene, Current Science, 79(3), pp. 373-377.

Chavez, P.S., 1996. Image-based atmospheric correction-revisited and improved, Photogrammetric Engineering and Remote Sensing, 62(9), pp.1025-1036.

Danby, R.K. and Hik, D.S., 2007. Variability, contingency and rapid change in recent subarctic alpine treeline dynamics, Journal of Ecology, 95, pp. 352-363.

Dixon, R.K., Brown, S., Houghton, R.A., Solomon, A.M., Trexler, M.C. and Wisniewski, J., 1994. Carbon pools and flux of global forest ecosystems, Science, 263, pp. 185-189. 
Dubey, B., Yadav, R.R., Singh, J., and Chaturvedi, R., 2003. Upward shift of Himalayan pine in Western Himalaya, India, Current Science, 85(8), pp. 1135-1136.

Geological Survey of India (GSI), 1999. Inventory of Himalayan Glaciers.

Gorchakovsky, P.L. and Shiyatov, S.G., 1978. The upper forest limit in the mountains of the boreal zone of the USSR, Arctic and Alpine Research, 10, pp. 349-363.

Gottfried, M., Pauli, H. and Grabherr, G., 1998. Prediction of vegetation patterns at the limits of plant life: A new view of the alpine-nival ecotone, Arctic and Alpine Research, 30: pp. 207221.

Grabherr, G., Gotfried, M. and Pauli, H., 1994. Climate effects on mountain plants, Nature 369: p.448.

Grace, J., Bernigger, F. and Nagy, L., 2002. Impacts of climate change on the treeline, Annals of Botany, 90, pp. 537-544.

Hijmans, R.J., Cameron, S.E., Parra, J.L., Jones, P.G., Jarvis, A., 2005. Very high resolution interpolated climate surfaces for global land areas. International Journal of Climatology 25: 19651978.

Holtmeier, F.K. and Broll, G., 2005. Sensitivity and response of northern hemisphere altitudinal and polar treelines to environmental change at landscape and local scales, Global Ecology and Biogeography, 14, pp. 395-410.

Indian Meteorological Department (IMD), 1989. Climate of Uttar Pradesh, pp. 372-375.

Jönsson, P. and Eklundh, L., 2004. TIMESAT - a program for analysing time-series of satellite sensor data, Computers and Geosciences, 30, pp.833-845.

Kar, R., Ranhotra, P. S., Bhattacharyya, A. and Sekar, B., 2002. Vegetation vis-à-vis climate and glacial fluctuations of the Gangotri Glacier since the last 2000 years, Current Science, 82(3), pp. 347-351.

Kawabata, A., Ichii, K. and Yamaguchi, Y., 2001. Global monitoring of the interannual changes in vegetation activities using NDVI and its relationships to temperature and precipitation, International Journal of Remote Sensing, 22, pp. 1377-1382.

Körner, C. and Paulsen, J., 2004. A world-wide study of high altitude treeline temperatures, Journal of Biogeography, 31, pp. 713-732.

Kullman, L., 1979. Change and stability in the altitude of the birch tree-limit in the southern Swedish Scandes 1915-1975, Acta Phytogeography Suecica, 65, pp. 1-121.

Kullman, L., 1990. Dynamics of altitudinal tree-limits in Sweden: a review. Norsk Georgraphy Tidsskr, 44, pp. 103-116.

Kullman, L., 2004. The changing face of the alpine world, Global Change Newsletter, 57, pp. 12-14.
Kullman, L., 2007. Treeline population monitoring of Pinus sylvestris in the Swedish Scandes, 1973-2005: implications for treeline theory and climate change ecology, Journal of Ecology, 95 , pp. 41-52.

Leica, 2005. Erdas Imagine 9.0, Leica Geosystems Geospatial imagining (Norcross, Georgi:LLC).

Mukherjee, B.P. and Sangewar, C.V., 2001. Recession of Gangotri glacier through $20^{\text {th }}$ century. In Proc. of National Symp. on role of Earth sciences in integrated development and related societal issues (Lucknow, India: GSI).

Myneni, R.B., Nemani, R.R. and Running, S.W., $1997 \mathrm{~b}$. Estimation of global leaf area index and absorbed PAR using radiative transfer models, IEEE Trans. Geosci. Remote Sensing, $35,1380-1393$.

Myneni, R.B., Keeling, C.D. and Tucker, C.J., 1997a. Increased plant growth in the northern high latitudes from 1981 to 1991 , Nature, 386, pp. 698-702.

Naithani, A.K., Nainwal, H.C., Sati, K.K. and Prasad, C., 2001. Geomorphological evidences of retreat of the Gangotri glacier and its characteristics, Current Science, 80(1), pp. 87-94.

Panigrahy, S., Anitha, D., Kimothi, M.M. and Singh, S.P., 2010. Treeline change detection using topographic map and satellite imagery, Tropical Ecology, 51(1): pp.87-91.

Ramirez, J. and Jarvis, A., 2008. High Resolution Statistically Downscaled Future Climate Surfaces.

Rees, G., Brown, I., Mikkola, K., Virtanen, T. and Werkman, B., 2002. How can the dynamics of the tundra-taiga boundary be remotely monitored? Ambio. Special Report 12, Tundra-Taiga Treeline Research, 56-62.

Shankar, R. and Srivastava, D., 1999. Invited papers, Symp. Snow, Ice and Glaciers: A Himalayan Perspective, GSI, Lucknow, 9-11 March, pp. 1-7.

Singh, J. and Yadav, R.R., 2000. Tree-ring indications of recent glacier fluctuations in Gangotri, western Himalaya, India, Current Science, 79(11), pp. 1598-1601.

Srivastava, A.K., Rajeevan, M. and Kshirsagar, S.R., 2008. Development of a High Resolution Daily Gridded Temperature Data Set (1969-2005) for the Indian Region, NCC Report.

Steven, M.D., Malthus, T.J., Baret, F., Xu, H. and Chopping, M.J., 2003. Intercalibration of vegetation indices from different sensor systems, Remote Sensing of Environment, 88, pp. 412-422.

Stockwell, D.R.B., and Peters, D.P., 1999.The GARP modelling system: Problems and solutions to automated spatial prediction, Int. Jr. of Geographic Information Systems, 13: pp.143-158.

Web1:www.gdem.aster.ersdac.or.jp/ASTER_GDEM_Validation_ Summary_Report

Xu, B., Gong, P. and Pu, R., 2003. Crown closure estimation of oak savannah in a dry season with Landsat TM imagery: 
International Archives of the Photogrammetry, Remote Sensing and Spatial Information Sciences, Volume XXXVIII-8/W20, 2011 ISPRS Bhopal 2011 Workshop, 8 November 2011, Bhopal, India

ISPRS Archives XXXVIII- 8/W20; Workshop Proceedings: Earth Observation for Terrestrial Ecosystems

comparison of various indices through correlation analysis, International Journal of Remote Sensing, 24, pp. 1811-1822.

Zhang, Y., Xu, M., Adams, J. and Wang, X., 2008. The trend of treeline on the northern slope of Changbai Mountain, Int. Journal of Remote Sensing. 30, pp. 1327 - 1340.

\section{ACKNOWLEDGEMENTS}

The authors duly acknowledge the support extended by Dr R. R. Navalgund, Director, SAC (ISRO), Ahmedabad. The project has been carried out under EOAM of ISRO, which is gratefully acknowledged. The Landsat data facility and ASTER GDEM product of METI and NASA are also duly acknowledged. 